\title{
Use of Direct-to-Consumer Telemedicine to Access Mental Health Services
}

\author{
Jessica A. Hohman, MD, MSc, MSc ${ }^{1,2}$ D, Kathryn A. Martinez, PhD, MPH', \\ Amit Anand, $M D^{3}$, Mark Rood, $M D^{2}$, Trejeeve Martyn, $M D^{4}$, Susannah Rose, $P h D^{5}$, and \\ Michael B. Rothberg, $M D, M P H^{1,2}$
} ${ }^{1}$ Cleveland Clinic Center for Value-Based Care Research, Cleveland, OH, USA; ${ }^{2}$ Cleveland Clinic Community Care, Cleveland, OH, USA;
${ }^{3}$ Cleveland Clinic Center for Behavioral Health, Cleveland, OH, USA; ${ }^{4} \mathrm{Cleveland}$ Clinic Heart and Vascular Institute, Cleveland, OH, USA; ${ }^{5} \mathrm{O}$ (ffice of
Patient Experience, Cleveland Clinic, Cleveland, OH, USA.

BACKGROUND: The coronavirus disease 2019 pandemic has contributed to growing demand for mental health services, but patients face significant barriers to accessing care. Direct-to-consumer(DTC) telemedicine has been proposed as one way to increase access, yet little is known about its pre-pandemic use for mental healthcare.

OBJECTIVE: To characterize patients, providers, and their use of a large nationwide DTC telemedicine platform for mental healthcare.

DESIGN: Retrospective cross-sectional study.

SETTING: Mental health encounters conducted on the American Well DTC telemedicine platform from 2016 to 2018.

PARTICIPANTS: Patients and physicians.

MAIN MEASURES: Patient measures included demographics, insurance report, and number of visits. Provider characteristics included specialty, region, and number of encounters. Encounter measures included wait time, visit length and timing, out-of-pocket payment, coupon use, prescription outcome, referral receipt, where care otherwise would have been sought, and patient satisfaction. Factors associated with five-star physician ratings and prescription receipt were assessed using logistic regression.

KEY RESULTS: We analyzed 19,270 mental health encounters between 6708 patients and 1045 providers. Visits were most frequently for anxiety (39.1\%) or depression (32.5\%), with high satisfaction (4.9/5) across conditions. Patients had a median 2.0 visits for psychiatry (IQR 1.0-3.0) and therapy (IQR 1.0-5.0), compared to 1.0 visit (IQR 1.0-1.0) for urgent care. High satisfaction was positively correlated with prescription receipt (OR 1.89, 95\% CI 1.54-2.32) and after-hours timing (aOR 1.18, 95\% CI 1.02-1.36). Prescription rates ranged from $79.6 \%$ for depression to $32.2 \%$ for substance use disorders. Prescription receipt was associated with increased visit frequency (aOR 1.95, 95\% CI 1.57-2.42 for $\geq 3$ visits).

CONCLUSIONS: As the burden of psychiatric disease grows, DTC telemedicine offers one solution for extending access to mental healthcare. While most encounters were one-off, evidence of some continuity in psychiatry and therapy visits-as well as overall high patient

Received May 6, 2021

Accepted December 14, 2021

Published online January 29, 2022 satisfaction-suggests potential for broader DTC telemental health use.

J Gen Intern Med 37(11):2759-67

DOI: $10.1007 / \mathrm{s} 11606-021-07326-y$

(C) The Author(s) under exclusive licence to Society of General Internal Medicine 2022

\section{INTRODUCTION}

Prior to the coronavirus disease 2019 (COVID-19) pandemic, roughly one in five adults in the US reported suffering from mental illness. ${ }^{1}$ The pandemic has driven further demand for behavioral health services, while access to mental healthcare has decreased. ${ }^{2-5}$ Significant barriers to access exist: limited insurance coverage, high costs, provider shortages, and long wait times. There are no psychiatrists practicing in many U.S. counties. ${ }^{6}$ By some estimates, two-thirds of primary care physicians are unable to connect patients to outpatient mental healthcare, forcing them to assume central roles in behavioral health provision ${ }^{5}$; meanwhile, patients without regular care providers increasingly turn to emergency departments (ED) for mental healthcare. ${ }^{7-9}$ Among adults who are able to access behavioral health services, $40 \%$ experience wait times longer than 1 week, and half travel $\geq 1 \mathrm{~h}$ for care. ${ }^{3}$

In response to this mismatch in supply and demand, a number of telemental health models have emerged, including video conferencing and electronic consultation with specialists. ${ }^{10-13}$ Although use of telemedicine for mental health remained rare prior to the pandemic - representing $<1 \%$ of visits, studies have suggested that telemental health produces comparable outcomes to traditional in-person care; however, these studies have focused on a limited range of diagnoses, underserved populations, or collaborative or consultative telemedicine models. ${ }^{12,14-25}$

Direct-to-consumer (DTC) telemedicine is distinct from those models in that it is neither provider-initiated nor specifically designed for mental healthcare. DTC telemedicine instead allows patients to connect with physicians around the clock via synchronous video visits. ${ }^{13,26-28}$ It offers a convenient, affordable way to improve access for many health 
conditions; insurance is not required, and out-of-pocket costs are generally lower than for traditional care. ${ }^{26,29}$ Employers and payers frequently partner with DTC telemedicine companies to offer services. ${ }^{27}$

Historically, patients have used DTC telemedicine to address minor, urgent concerns, such as respiratory or urinary tract infections. ${ }^{26,30-32}$ Yet as DTC telemedicine has expanded over the last decade, so too has the scope of conditions for which patients can receive care, which increasingly includes mental health concerns. While patients can request visits with psychiatrists or therapists, patients with behavioral health needs may also be cared for by urgent care physicians.

To date, no study has described mental healthcare provision via DTC telemedicine. ${ }^{29}$ Given increased demand for both telemedicine and mental health services in the continuing wake of the COVID-19 pandemic and the rapid expansion of DTC models, understanding patterns of mental healthcare delivery via DTC platforms is needed. The objectives of our study were to characterize patients, providers, and their use of a large nationwide DTC telemedicine platform for mental healthcare, and to assess factors associated with prescription receipt and patient satisfaction.

\section{METHODS}

We performed a retrospective cross-sectional study of mental health encounters conducted on American Well's telemedicine platform between July 2016 and July 2018. This study was approved by Cleveland Clinic's Institutional Review Board.

\section{Data Source and Collection Procedures}

American Well's web/mobile platform uses HIPAAcompliant technology to connect patients with healthcare providers for synchronous video encounters.

When patients log in, they provide demographic information and choose a visit type: urgent care or behavioral health. Those who select behavioral health then choose psychiatry or therapy. The cost (without insurance) is $\$ 199$ for a psychiatry visit and $\$ 85$ for therapy, and appointments-while not instantaneous - can usually be scheduled for the same day. Alternatively, patients can connect immediately to an urgent care provider for $\$ 69$ (without insurance).

Providers are not associated with any particular medical group or health system. Employment agreements are heterogeneous, with some providers salaried and others paid per hour or per visit. Providers are drawn from around the country and vary in how much they work and when, with the average provider available $10 \mathrm{~h}$ per week. A detailed description of this platform has been published previously. ${ }^{26}$

\section{Mental Health Diagnoses}

Mental health visits were identified via International Classification of Diseases, Tenth Revision, Clinical
Modification(ICD10-CM) diagnosis codes. Up to seven codes could be entered per visit. We did not distinguish between primary versus secondary diagnoses. We assessed the 12 most common mental health diagnoses. A psychiatrist and two internists reviewed ICD-10 codes, which were grouped into the following categories: adjustment disorders, depressive disorders, anxiety disorders, mood disorders not otherwise specified (NOS), bipolar disorder, schizophrenia and psychotic disorders, post-traumatic stress disorder (PTSD) and other stress disorders, obsessive-compulsive disorder (OCD), attention-deficit/hyperactivity disorder (ADHD), nicotine use disorder, alcohol use disorder, substance use disorders, sleep disorders, and sexual disorders (see Appendix Table 1). Each diagnostic category was treated as an independent dichotomous variable.

\section{Patient Measures}

Patient measures included age, gender, geographic region, insurance, and number of visits.

\section{Provider Measures}

Provider characteristics included specialty and geographic region. We categorized physicians as psychiatrists versus urgent care providers. We separately examined mental health professionals available via the therapy option, as none were physicians. We captured number of visits per provider.

\section{Encounter Measures}

Encounter measures included visit timing, wait time, patient out-of-pocket contribution, coupon use, visit length, prescription outcome, referral receipt, follow-up requested, alternative care site, and patient satisfaction. Visit timing was categorized as regular business hours ( 7 a.m. -5 p.m. weekdays), lunchtime (12 p.m.-2 p.m. weekdays), or after hours (on weekdays or anytime during weekends). Visit length was determined by the time that the patient was connected to the provider, as recorded by the platform. Visits shorter than 1 minute were excluded. Patient out-of-pocket contribution and coupon use for free/ reduced-cost care were also recorded. Coupons are frequently offered by American Well, payers, and employers to encourage platform use.

Prescriptions were identified via National Drug Codes. Physicians could record up to seven medications. The Ryan Haight Act restricted DTC telemedicine physicians from prescribing controlled substances for patients in the absence of an in-person evaluation during the study period. ${ }^{33}$ Some controlled substances, like methylphenidate and buprenorphine, are commonly used treatments for certain mental health conditions and were not prescribed via DTC telemedicine.

We also examined whether patients received a referral/ follow-up request. Additionally, we noted where patients reported they would have otherwise sought care. Patient satisfaction was ascertained at the conclusion of each encounter 
on a scale of 1 to 5 stars (with 5 being most satisfied and 1 not satisfied at all). We dichotomized this as receiving 5 stars versus not since most patients rated their providers with 5 stars. ${ }^{26,31,32}$

\section{Analysis}

For patient, provider, and encounter measures, we reported frequencies (percentages) and measures of central tendency. We also described differences in prescribing patterns between psychiatrists versus urgent care physicians for the ten conditions for which medications were most commonly prescribed, using chi-square tests where appropriate. We then reported the most frequently prescribed medications by condition.

Finally, we estimated mixed-effects logistic regression models, accounting for clustering by provider. We modeled both odds of prescription receipt and of rating a provider five stars. Models included the physician, patient, and encounter characteristics described above.

All analyses were performed using SAS 9.4.

\section{RESULTS}

The sample included 19,270 mental health encounters between 6708 patients and 1063 providers. During the study period, mental health diagnoses constituted only $1.7 \%$ of visits to physicians via the urgent care option.
Encounters were most frequently for anxiety $(39.1 \%)$, followed by depressive (32.5\%), adjustment (23.0\%), bipolar (6.4\%), and PTSD/stress disorders (5.1\%). Schizophrenia and psychotic disorders accounted for $<1 \%$ of visits.

\section{Provider and Patient Characteristics}

Provider and patient characteristics are shown in Table 1.

Among physicians in our sample, 74 were psychiatrists. Among physicians available via the urgent care option, 414 were generalists (emergency medicine, internal medicine, family medicine, or pediatrics) and 60 were specialists (primarily dermatologists).

The 519 mental health professionals who were available for therapy self-identified as 141 psychologists, 4 social workers, 29 counselors, and 345 therapists.

Of the 19,270 mental health visits examined, $21.6 \%$ were seen by psychiatry, $22.2 \%$ by urgent care providers, and $56.2 \%$ by mental health professionals for therapy. Over the study period, psychiatrists had a median 71.0 (IQR 25.0-159.0) visits with patients as compared to 12.0 (IQR 4.0-30.0) encounters for urgent care providers and 34.0 (IQR 11.0-95.0) encounters for mental health professionals providing therapy.

Overall, 59.4\% of patients were female with a median age of 34.0 years (IQR 28.0-43.0). Patients selecting the urgent care option were more likely to have used the platform only once during the study period ( $83.1 \%$ vs. $42.2 \%$ of those who were seen for psychiatry or therapy, $p<.0001$ ). Of patients

Table 1 Patient and Physician Characteristics for Mental Health Encounters, 2016-2018

\begin{tabular}{|c|c|c|c|c|}
\hline \multirow[t]{2}{*}{ Variable } & \multicolumn{4}{|l|}{ No. $(\%)$} \\
\hline & All & Psychiatry & Urgent care & Therapy \\
\hline \multicolumn{5}{|l|}{ Patient characteristics $(\mathrm{N}=6708)$} \\
\hline Female & $3983(59.4)$ & $889(60.4)$ & $1799(53.8)$ & $1562(68.4)$ \\
\hline \multicolumn{5}{|l|}{ Age, y } \\
\hline$<18$ & $204(3.0)$ & $25(1.7)$ & $56(1.7)$ & $127(5.6)$ \\
\hline $18-29$ & $2084(31.1)$ & $567(38.6)$ & $1009(30.2)$ & $644(28.2)$ \\
\hline $30-39$ & $2354(35.1)$ & $520(35.4)$ & $1185(35.4)$ & $797(34.9)$ \\
\hline $40-49$ & $1267(18.9)$ & $224(15.2)$ & $705(21.1)$ & $389(17.0)$ \\
\hline $50-64$ & $755(11.3)$ & $131(8.9)$ & $367(11.0)$ & $302(13.2)$ \\
\hline 65 and over & $44(0.7)$ & $4(0.3)$ & $23(0.7)$ & $24(1.1)$ \\
\hline Insurance reported & $4799(71.6)$ & $954(64.9)$ & $2255(67.4)$ & $1839(80.6)$ \\
\hline \multicolumn{5}{|l|}{ Geographic region } \\
\hline Northeast & $1137(17.0)$ & $263(17.9)$ & $452(13.5)$ & $492(21.6)$ \\
\hline Midwest & $1419(21.2)$ & $260(17.7)$ & $744(22.2)$ & $486(21.3)$ \\
\hline South & $2550(38.0)$ & $635(43.2)$ & $1223(36.6)$ & $870(38.1)$ \\
\hline West & $1602(23.9)$ & $313(21.3)$ & $926(27.7)$ & $435(19.1)$ \\
\hline \multicolumn{5}{|l|}{ Number of telemedicine visits during the study period } \\
\hline One & $4063(60.6)$ & $633(43.0)$ & $2779(83.1)$ & $952(41.7)$ \\
\hline Two & $983(14.7)$ & $322(21.9)$ & $370(11.1)$ & $347(15.2)$ \\
\hline Three & $452(6.7)$ & $158(10.7)$ & $105(3.1)$ & $206(9.0)$ \\
\hline Four & $295(4.4)$ & $109(7.4)$ & $58(1.7)$ & $151(6.6)$ \\
\hline Five & $184(2.7)$ & $60(4.1)$ & $18(0.5)$ & $106(4.6)$ \\
\hline Six or more & $731(10.9)$ & $189(12.9)$ & $15(0.5)$ & $521(22.8)$ \\
\hline \multicolumn{5}{|l|}{ Provider characteristics $(\mathrm{N}=1064)$} \\
\hline \multicolumn{5}{|l|}{ Geographic region } \\
\hline Northeast & $217(20.4)$ & $23(31.1)$ & $88(18.6)$ & $107(20.6)$ \\
\hline Midwest & $173(16.3)$ & $11(14.9)$ & $83(17.5)$ & $79(15.2)$ \\
\hline South & $420(39.5)$ & $24(32.4)$ & $193(40.7)$ & $205(39.5)$ \\
\hline West & $254(23.9)$ & $16(21.6)$ & $110(23.2)$ & $128(24.7)$ \\
\hline Number of encounters per provider, median (IQR) & $31.0(9.0-87.0)$ & $71.0(25.0-159.0)$ & $12.0(4.0-30.0)$ & $34.0(11.0-95.0)$ \\
\hline
\end{tabular}


Table 2 Mental Health Encounter Characteristics, 2016-2018

\begin{tabular}{|c|c|c|c|c|}
\hline \multirow[t]{2}{*}{ Variable } & \multicolumn{4}{|l|}{ No. $(\%)$} \\
\hline & $\begin{array}{l}\text { All } \\
N=19,270\end{array}$ & $\begin{array}{l}\text { Psychiatry } \\
N=4165\end{array}$ & $\begin{array}{l}\text { Urgent care } \\
N=4276\end{array}$ & $\begin{array}{l}\text { Therapy } \\
N=\mathbf{1 0 , 8 2 8}\end{array}$ \\
\hline \multicolumn{5}{|l|}{ Encounter characteristics } \\
\hline \multicolumn{5}{|l|}{ Number of encounters, by year, $N(\%)$} \\
\hline 2016 & $1791(9.3)$ & $126(3.0)$ & $903(21.1)$ & $762(7.0)$ \\
\hline 2017 & $8744(45.4)$ & $2093(50.2)$ & $2186(51.1)$ & $4464(41.2)$ \\
\hline $2018^{*}$ & $8735(45.3)$ & $1946(46.8)$ & $1187(27.8)$ & $5602(51.7)$ \\
\hline \multicolumn{5}{|l|}{ Encounter timing, $N(\%)$} \\
\hline After hours ${ }^{\dagger}$ & $10,094(52.4)$ & $2873(69.0)$ & $2276(53.2)$ & $4945(45.7)$ \\
\hline Wait time (min), median (IQR) & $2.8(1.3-6.2)$ & $3.1(1.4-6.3)$ & $3.5(1.7-8.3)$ & $2.4(1.1-5.6)$ \\
\hline Encounter length (min), median (IQR) & $36.9(9.2-48.7)$ & $15.7(9.3-30.5)$ & $6.2(3.8-10.0)$ & $46.9(41.5-53.3)$ \\
\hline Patient out-of-pocket cost for visit (\$), median (IQR) & $25.0(0.0-79.0)$ & $90.0(0.0-145.0)$ & $39.0(1.0-59.0)$ & $20.0(0.0-79.0)$ \\
\hline Coupon used, $N(\%)$ & $2657(13.8)$ & $1313(31.5)$ & $461(10.8)$ & $883(8.2)$ \\
\hline Prescription received, $N(\%)$ & $6076(31.5)$ & $3133(75.2)$ & $2943(68.8)$ & \\
\hline Referral given & $241(1.3)$ & $87(2.1)$ & $126(3.0)$ & $28(0.3)$ \\
\hline \multicolumn{5}{|l|}{ Mental health diagnosis, $N(\%)$} \\
\hline Adjustment disorders & $4428(23.0)$ & $118(2.8)$ & $547(12.8)$ & $3763(34.8)$ \\
\hline Anxiety disorders & $7543(39.1)$ & $1716(41.2)$ & $1847(43.2)$ & $3980(36.8)$ \\
\hline PTSD/stress disorders & $977(5.1)$ & $200(4.8)$ & $41(1.0)$ & $736(6.8)$ \\
\hline OCD & $304(1.6)$ & $120(2.9)$ & $17(0.4)$ & $167(1.5)$ \\
\hline Depressive disorders & $6264(32.5)$ & $2235(53.7)$ & $937(21.9)$ & $3092(28.6)$ \\
\hline Bipolar disorder & $1224(6.4)$ & $654(15.7)$ & $112(2.6)$ & $458(4.2)$ \\
\hline Mood NOS disorders & $171(0.9)$ & $8(0.2)$ & $33(0.8)$ & $130(1.2)$ \\
\hline ADHD & 689 (3.6) & $277(6.7)$ & $106(2.5)$ & $306(2.8)$ \\
\hline Nicotine use disorder & $352(1.8)$ & $5(0.1)$ & $326(7.6)$ & $21(0.2)$ \\
\hline Alcohol use disorder & $311(1.6)$ & $92(2.2)$ & $38(0.9)$ & $181(1.7)$ \\
\hline Substance use disorders & $219(1.1)$ & $62(1.5)$ & $53(1.2)$ & $104(1.0)$ \\
\hline Sleep disorders & $214(1.1)$ & $42(1.0)$ & $147(3.4)$ & $25(0.2)$ \\
\hline Schizophrenia/psychotic disorders & $66(0.3)$ & $42(1.0$ & $1(0.0)$ & $23(0.2)$ \\
\hline Sexual disorders & $62(0.3)$ & $0(0.0)$ & $50(1.2)$ & $12(0.1)$ \\
\hline Two or more mental health diagnoses received, $N(\%)$ & $3538(18.4)$ & $1204(28.9)$ & $234(5.5)$ & $2100(19.4)$ \\
\hline Patient rating of provider, mean (SD) & $4.9(0.5)$ & $4.9(0.4)$ & $4.8(0.8)$ & $4.9(0.4)$ \\
\hline \multicolumn{5}{|l|}{ Where patients would have sought care otherwise, $N(\%)$} \\
\hline Emergency department & $206(1.1)$ & $35(0.8)$ & $116(2.7)$ & $55(0.5)$ \\
\hline Doctor's office & $3362(17.5)$ & $1069(25.7)$ & $1045(24.4)$ & $1248(11.5)$ \\
\hline Urgent care/retail clinic & $1050(5.4)$ & $121(2.9)$ & $741(17.3)$ & $188(1.7)$ \\
\hline Done nothing & $7633(39.6)$ & $1559(37.4)$ & $907(21.2)$ & $5166(47.7)$ \\
\hline Other & $7019(36.4)$ & $1381(33.2)$ & $1467(34.3)$ & $4171(38.5)$ \\
\hline
\end{tabular}

Abbreviations: PTSDpost-traumatic stress disorder, OCDobsessive-compulsive disorder, NOS not otherwise specified, ADHD attention-deficit/ hyperactivity disorder

*2018 volumes are truncated, including only up to July 2018

${ }^{4}$ After-hours encounter timing refers to encounters that occur during the weekend or outside of traditional business hours (7 a.m.-5 p.m.) during the week

$n / a=$ Not Applicable

who sought psychiatry or therapy, over half had two or more visits.

\section{Encounter Characteristics}

Over time, mental health encounter volumes increased, as did the proportion of patients who chose psychiatry and therapy (Table 2).

Insurance use was frequent (71.6\%), and $13.8 \%$ of visits involved coupons for free/reduced-cost care. The median outof-pocket payment for psychiatry was $\$ 90$ (IQR $\$ 0-\$ 145$ ), as compared to \$39 (IQR \$1-\$59) for urgent care and \$20 (IQR $\$ 0-\$ 79)$ for talk therapy.

The majority of mental health encounters occurred outside of regular business hours $(58.8 \%)$ or during lunchtime (15.3\%). Wait times were short (median $2.8 \mathrm{~min}$, IQR 1.36.2). Median visit length with psychiatrists was 15.7 (IQR 9.3-30.5) min, as compared to 6.2 (IQR 3.8-10.0) $\mathrm{min}$ with urgent care providers and 46.9 (IQR 41.5-53.3) min with mental health professionals for therapy. Psychiatrists prescribed medications at higher rates than urgent care providers ( $75.2 \%$ vs. $68.8 \%)$, and patients reported high satisfaction $(4.9 / 5$, SD: 0.5$)$ with telemedicine providers across specialties and diagnoses.

If they had not used this platform, $39.6 \%$ of patients reported they would have done nothing, $1.1 \%$ would have gone to the ED, and $5.4 \%$ would have gone to an urgent care/retail clinic.

\section{Prescribing Patterns}

Prescribing rates in psychiatry versus urgent care for the top ten mental health conditions appear in Fig. 1. Prescribing rates were high for adjustment $(63.9 \%)$, anxiety $(74.0 \%)$, depressive $(79.6 \%)$, bipolar $(77.6 \%), \mathrm{PTSD} /$ stress $(68.9 \%)$, OCD (70.8\%), and nicotine use disorders $(74.9 \%)$. Prescribing rates were lower for ADHD (42.8\%), alcohol use (50.0\%), and substance use disorders $(32.2 \%)$. The most frequently prescribed medications by diagnosis are presented in Appendix Table 2. 


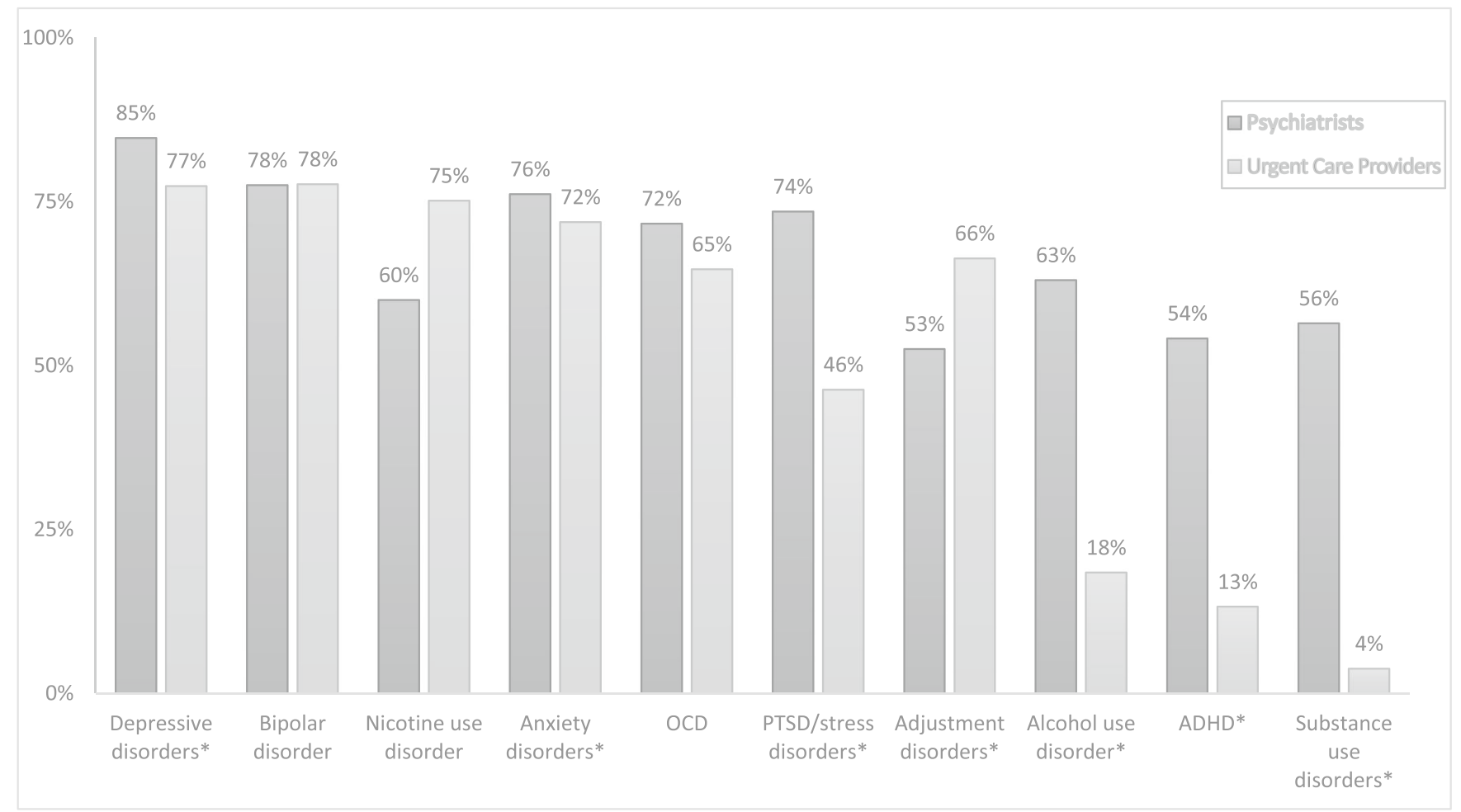

Figure 1 Prescribing rates by specialty for the top ten mental health conditions for which medications were prescribed. Abbreviations: PTSD, post-traumatic stress disorder; OCD, obsessive-compulsive disorder; ADHD, attention-deficit/hyperactivity disorder. *Statistically significant at $p<0.05$.

\section{Predictors of Receiving a Prescription}

In our adjusted analysis (Table 3), anxiety (aOR 1.61, 95\% CI 1.09-2.38), depressive (aOR 2.36, 95\% CI 1.62-3.43), bipolar (aOR 2.21, 95\% CI 1.46-3.34), and nicotine use (aOR 2.16, 95\% CI 1.08-4.35) disorders were associated with higher odds of receiving a medication. Visits for ADHD (aOR 0.40, 95\% CI 0.25-0.64), substance use (aOR 0.25, 95\% CI 0.12-0.56), alcohol use (aOR 0.42, 95\% CI 0.27-0.66), and sexual (aOR 0.16 , 95\% CI $0.07-0.38$ ) disorders were less likely to result in prescriptions. Compared to 18-29-year olds, patients aged 65 and over were less likely to receive prescriptions (aOR 0.32, 95\% CI 0.19-0.55). Finally, reporting insurance information (aOR 1.35, 95\% CI 1.08-1.70) and having more visits (aOR 2.37, 95\% CI 1.95-2.87 for two visits; aOR 1.95, 95\% CI 1.57-2.42 for three or more visits) were associated with higher odds of receiving a medication.

\section{Predictors of Providers Receiving a Five-Star Rating}

Visits resulting in a prescription (OR 1.89, 95\% CI 1.54-2.32) and those occurring after hours (aOR 1.18, 95\% CI 1.02-1.36) had higher odds of resulting in a five-star rating, whereas visits for diagnoses of substance use (OR 0.30, 95\% CI 0.15-0.58) or sexual (OR $0.34,95 \%$ CI $0.14-0.79$ ) disorders were associated with lower odds of receiving five stars (Table 3 ).

\section{DISCUSSION}

DTC telemedicine provides convenient access to talk therapy and pharmacotherapy for common mental health conditions. Our analyses of behavioral health encounters conducted on a large nationwide DTC telemedicine platform from 2016 to 2018 found that the majority of patient visits were for talk therapy, with use growing for both psychiatry and therapy. The most common visit diagnoses were adjustment, depressive, and anxiety disorders, for which prescribing rates of antidepressants were high. Patients sought both episodic and longitudinal care, and visit lengths and prescribing patterns appeared comparable to in-person encounters. ${ }^{34-36}$ Patient satisfaction with providers was high.

The emergence of COVID-19 has driven increased demand for mental healthcare, with roughly 2 in 5 adults now reporting symptoms of anxiety/depression, and ED visits for suicidality and overdoses rising. ${ }^{5}$ Yet in-person mental health provider staffing is decreasing nationwide. ${ }^{5}$ Meanwhile, DTC telemedicine platforms-including behavioral healthfocusedapplications - are proliferating, representing an alternative means of meeting this demand. ${ }^{37}$

Recent studies highlight telemedicine's potential to improve access across medical conditions. ${ }^{16,29,38-40}$ For mental healthcare, specifically, DTC telemedicine may enhance access in several ways. First, it extends the current supply of both mental health professionals and generalists comfortable treating psychiatric disorders into geographically underserved 
Table 3 Mixed-Effects Logistic Regression, Odds of Receiving a Prescription, and Odds of Receiving a Five-Star Patient Rating

\begin{tabular}{|c|c|c|c|c|}
\hline \multirow[t]{2}{*}{ Variable } & \multicolumn{2}{|c|}{ Prescription receipt } & \multicolumn{2}{|c|}{ Receipt of five-star rating } \\
\hline & aOR & $95 \% \mathrm{CI}$ & aOR & $95 \% \mathrm{CI}$ \\
\hline \multicolumn{5}{|l|}{ Patient characteristics } \\
\hline Female (versus male) & 1.01 & $0.89-1.16$ & 0.88 & $0.76-1.01$ \\
\hline \multicolumn{5}{|l|}{ Age } \\
\hline $18-29$ & Ref & - & Ref & - \\
\hline $30-39$ & 1.13 & $0.99-1.30$ & 0.99 & $0.83-1.19$ \\
\hline $40-49$ & 0.99 & $0.84-1.16$ & 0.94 & $0.76-1.16$ \\
\hline $50-64$ & 0.87 & $0.60-1.27$ & 0.45 & $0.34-0.61$ \\
\hline $65+$ & 0.32 & $0.19-0.55$ & 0.44 & $0.15-1.26$ \\
\hline \multicolumn{5}{|l|}{ Number of telemedicine visits during the study period } \\
\hline One & Ref & - & Ref & - \\
\hline Two & 2.37 & $1.95-2.87$ & 1.11 & $0.88-1.40$ \\
\hline Three or more & 1.95 & $1.57-2.42$ & 1.08 & $0.87-1.33$ \\
\hline \multicolumn{5}{|l|}{ Physician characteristics } \\
\hline \multicolumn{5}{|l|}{ Specialty } \\
\hline Psychiatry (versus urgent care) & 0.84 & $0.62-1.15$ & 0.92 & $0.72-1.18$ \\
\hline \multicolumn{5}{|l|}{ Geographic region } \\
\hline Northeast & Ref & - & Ref & - \\
\hline Midwest & 1.31 & $0.88-1.95$ & 0.76 & $0.56-1.02$ \\
\hline South & 1.51 & $1.06-2.16$ & 0.84 & $0.63-1.12$ \\
\hline West & 1.31 & $0.97-1.79$ & 0.80 & $0.61-1.05$ \\
\hline \multicolumn{5}{|l|}{ Encounter characteristics } \\
\hline Insurance reported (versus not) & 1.35 & $1.08-1.70$ & 1.07 & $0.86-1.34$ \\
\hline \multicolumn{5}{|l|}{ Encounter timing } \\
\hline After hours ${ }^{*}$ (versus business hours) & 1.18 & $0.95-1.47$ & 1.18 & $1.02-1.36$ \\
\hline Prescription received & $\mathrm{n} / \mathrm{a}$ & $\mathrm{n} / \mathrm{a}$ & 1.89 & $1.54-2.32$ \\
\hline \multicolumn{5}{|l|}{ Diagnoses (versus not) } \\
\hline Adjustment disorders & 1.17 & $0.77-1.78$ & 0.90 & $0.57-1.42$ \\
\hline Anxiety disorders & 1.61 & $1.09-2.38$ & 0.99 & $0.71-1.40$ \\
\hline Depressive disorders & 2.36 & $1.62-3.43$ & 1.02 & $0.75-1.39$ \\
\hline Bipolar disorder & 2.21 & $1.46-3.34$ & 0.90 & $0.57-1.42$ \\
\hline PTSD/stress disorders & 1.17 & $0.64-2.15$ & 0.78 & $0.48-1.27$ \\
\hline ADHD & 0.40 & $0.25-0.64$ & 1.05 & $0.65-1.69$ \\
\hline Substance use disorders & 0.25 & $0.12-0.56$ & 0.30 & $0.15-0.58$ \\
\hline Nicotine use disorder & 2.16 & $1.08-4.35$ & 0.67 & $0.39-1.16$ \\
\hline Alcohol use disorder & 0.42 & $0.27-0.66$ & 0.75 & $0.46-1.23$ \\
\hline OCD & 1.09 & $0.60-1.97$ & 1.00 & $0.53-1.87$ \\
\hline Sleep disorders & 0.72 & $0.43-1.19$ & 0.83 & $0.46-1.47$ \\
\hline Mood NOS disorders & 1.59 & $0.73-3.47$ & 1.14 & $0.36-3.59$ \\
\hline Schizophrenia/psychotic disorders & 2.79 & $0.98-7.96$ & 0.80 & $0.41-1.57$ \\
\hline Sexual disorders & 0.16 & $0.07-0.38$ & 0.34 & $0.14-0.79$ \\
\hline Encounter length (min) & 1.00 & $0.99-1.01$ & 1.00 & $1.00-1.01$ \\
\hline Two or more mental health diagnoses received (versus not) & 0.74 & $0.48-1.16$ & 0.97 & $0.64-1.48$ \\
\hline
\end{tabular}

*After-hours encounter timing refers to encounters that occur during the weekend or outside of traditional business hours (7 a.m.-5 p.m.) during the week

areas. Second, it may increase the overall availability of existing providers, particularly psychiatrists, as many were available part time after normal business hours, potentially in addition to their full-time jobs. Third, DTC telemedicine improves timeliness of access to mental healthcare, facilitating on-demand services as compared to average wait times of 25 days for in-person visits. ${ }^{41}$ Long wait times have been linked to ED utilization, where patients are more likely to leave without adequate psychiatric treatment. ${ }^{42,43}$ Finally, when asked where they would have otherwise sought care, $40 \%$ of patients reported that they would have done nothing; DTC telemedicine represents an attractive option to meet this population's unmet needs.

DTC telemedicine also addresses accommodation barriers to access for patients with difficulty attending frequent visits during work hours, or who desire convenient care from home ${ }^{44}$ Approximately $60 \%$ of behavioral health encounters occurred on evenings or weekends, compared to $48 \%$ of visits for other health concerns. ${ }^{45}$ After-hours visits were associated with higher satisfaction. Even during traditional business hours, we observed roughly $15 \%$ of virtual visits occurred during lunchtime, which may reflect the ease with which virtual encounters can be integrated into the work day.

Lastly, DTC telemedicine may help to overcome affordability barriers. ${ }^{46,47}$ While COVID-19 has brought greater reimbursement parity to telemedicine, it is unclear whether this will continue. ${ }^{2}$ DTC telemedicine's relative affordability could improve access for those with inadequate or no insurance coverage for behavioral health given its transparent pricing model and generally lower out-of-pocket costs than for inperson visits. ${ }^{29}$

Our results affirm that patients are highly satisfied with DTC virtual visits for mental healthcare, with the highest satisfaction rates noted among repeat patients. ${ }^{26}$ The care provided over the platform also appears comparable to inperson visits in terms of length and prescribing patterns. ${ }^{48-51}$ 
The average in-person therapy visit is $50-55 \mathrm{~min}$ long, similar to the 47 min that we observed ${ }^{52,53}$ Fifteen-minute visits are increasingly standard for in-person psychiatry, ${ }^{54,55}$ and we found televisits with psychiatrists lasted a median $16 \mathrm{~min}$. Moreover, we found prescriptions were generally guidelineconcordant.

Patients sought both acute and longitudinal care for common psychiatric conditions like adjustment, anxiety, and depressive disorders. Patients choosing the urgent care option (as opposed to behavioral health) had shorter visits and appeared to use this model for discrete needs (e.g., refilling medications); for these patients, DTC telemedicine may provide a bridge to in-person care or alternative access point when a regular care provider is not available. Among patients who sought psychiatry or therapy, however, over half returned for follow-up visits, with a quarter of those receiving therapy returning for five or more visits. This finding suggests that DTC telemedicine may substitute for in-person continuity care for some and represents a potential growth opportunity.

We found that $<1 \%$ of our sample was over age 65 , with patients over age 50 comprising a smaller portion of mental health patients than of patients seeking other telemedicine care. ${ }^{56}$ More research is needed to understand the poor uptake in this demographic. Wireless penetration and digital literacy have been suggested as potential explanations, although widespread telemedicine adoption during the pandemic may improve acceptability and comfort over time. ${ }^{57-59}$

Prior telemedicine studies in mental health have been limited to a single payer, a particular institution or practice, or certain populations, such as veterans, rural beneficiaries, or incarcerated individuals. ${ }^{56,60-64}$ These have established the non-inferiority in outcomes and patient satisfaction of more common provider-driven telemental health models, such as clinic-basedvideoconferencing, electronic consultation, or collaborative models in the assessment or treatment of specific behavioral health conditions, as compared to inperson visits. ${ }^{8,11,12,18,20-23,65-68}$ To our knowledge, this is the first study to characterize DTC telemedicine usage for mental health in a national population, irrespective of payer and across mental health diagnoses and provider specialties. Our results highlight the different providers and services patients can access through this model to address their mental health needs.

Our study has several limitations. The analysis was restricted to items captured for administrative purposes. We did not have visibility into physician documentation. This limited our ability to draw conclusions regarding the quality of care provided. Our analysis of platform users is also subject to selection bias. It remains unclear whether this platform was primarily a bridge to long-term in-person care versus a substitutive entity. Additionally, limited information available about telemedicine providers restricted our ability to draw broader conclusions about them. Research demonstrates substantial differences in access to behavioral healthcare by patient race/ethnicity. Unfortunately, as we had no information on patient race/ethnicity, we were unable to evaluate this. ${ }^{69} \mathrm{Be}-$ cause of restrictions governing controlled substance prescribing via DTC telemedicine during the study period, moreover, prescribing rates for conditions such as SUD and ADHD-where controlled substances are common treatments - may be artificially low. Finally, our study was performed on one large nationwide telemedicine platform, so it is unknown how generalizable these findings are to other DTC providers.

Our analysis confirms steady growth in DTC telemental health prior to the COVID-19 pandemic. ${ }^{16,56}$ Given the increasing burden of psychiatric disease during the pandemic, mental health professional shortages, and uneven insurance coverage, novel models for delivering mental health services are needed. ${ }^{8,70}$ DTC telemedicine platforms are rapidly expanding and offer one potential solution. Our findings suggest that there is growing patient interest in the timely, convenient, price transparent, and affordable mental healthcare that these platforms can provide. While most encounters were one-off rather than a substitute for longitudinal mental healthcare, some evidence of continuity in therapy and psychiatry visits as well as overall high patient satisfaction ratings suggest potential for broader use.

Supplementary Information The online version contains supplementary material available at https://doi.org/10.1007/s11606-02107326-y.

Acknowledgements: The authors of our study all meet the uniform criteria for authorship. All authors have seen and approved the final manuscript and participated in the design and execution of the study. To the best of our knowledge, no conflict of interest, financial or other, exists. This manuscript has not been previously published and is not under consideration in the same or substantially similar form in any other peer-reviewed media.

Corresponding Author: Jessica A. Hohman, MD, MSc, MSc; Cleveland Clinic Community Care, Cleveland, OH, USA (e-mail: hohmanj@ccf.org).

\section{Declarations:}

Conflict of Interest: The authors declare that they do not have a conflict of interest.

\section{REFERENCES}

1. Kessler RC, Angermeyer M, Anthony JC, De Graaf R, Demyttenaere K, Gasquet I, et al. Lifetime prevalence and age-of-onset distributions of mental disorders in the World Health Organization's World Mental Health Survey Initiative. World psychiatry. 2007;6(3):168.

2. National Institute of Mental Health. Mental Health Information: Statistics. National Institutes of Health. 2021. Available at: https://www.nimh. nih.gov/health/statistics. Accessed 4 Sept 2021.

3. National Council for Behavioral Health. 2018 Annual Report. National Council for Mental Wellbeing. 2018. Available at: https://www.thenationalcouncil.org/about/2018-annual-report-pdf. Accessed 8 Aug 2021.

4. Panchal N, Kamal R, Orgera K, Cox C, Garfield R, Hamel L, et al. The implications of COVID-19 for mental health and substance use. Kaiser family foundation. 2020 .

5. Dicken J. Behavioral Health: Patient Access, Provider Claims Payment, and the Effects of the COVID-19 Pandemic (GAO-21-437R). U.S. Government Accountability Office. 2021.Available at: https://www.gao. gov/assets/gao-21-437r.pdf.Accessed 4 May 2021 
6. New American Economy. The Silent Shortage: How Immigration Can Help Address the Large and Growing Psychiatrist Shortage in the United States. 2017. Available at: https://www.newamericaneconomy.org/ wpcontent/uploads/2017/10/NAE_PsychiatristShortage_V6-1.pdf. Accessed 30 Nov 2020.

7. Weiner S. Addressing the escalating psychiatrist shortage. In: Colleges AAoM, ed.

8. Bashshur RL, Shannon GW, Bashshur N, Yellowlees PM. The empirical evidence for telemedicine interventions in mental disorders. Telemedicine and e-Health. 2016;22(2):87-113.

9. Xierali IM, Tong ST, Petterson SM, Puffer JC, Phillips RL, Bazemore AW. Family physicians are essential for mental health care delivery. The Journal of the American Board of Family Medicine. 2013:26(2):114-5.

10. Shigekawa E, Fix M, Corbett G, Roby DH, Coffman J. The current state of telehealth evidence: a rapid review. Health Affairs. 2018;37(12):1975-82.

11. Brearly TW, Shura RD, Martindale SL, Lazowski RA, Luxton DD, Shenal BV, et al. Neuropsychological Test Administration by Videoconference: A Systematic Review and Meta-Analysis. Neuropsychol Rev. 2017;27(2):174-86.

12. Garcia-Lizana F, Munoz-Mayorga I. What about telepsychiatry? A systematic review. Prim Care Companion J Clin Psychiatry. 2010;12(2):PCC.09m00831.

13. Jain T, Mehrotra A. Comparison of Direct-to-Consumer Telemedicine Visits With Primary Care Visits. JAMA Network Open. 2020;3(12):e2028392-e.

14. Hilty DM, Ferrer DC, Parish MB, Johnston B, Callahan EJ, Yellowlees PM. The effectiveness of telemental health: a 2013 review. Telemed J E Health. 2013;19(6):444-54.

15. Huskamp HA, Busch AB, Souza J, Uscher-Pines L, Rose S, Wilcock A, et al. How Is Telemedicine Being Used In Opioid And Other Substance Use Disorder Treatment? Health Affairs. 2018;37(12):1940-7.

16. Mehrotra A, Huskamp HA, Souza J, Uscher-Pines L, Rose S, Landon BE et al. Rapid Growth In Mental Health Telemedicine Use Among Rural Medicare Beneficiaries, Wide Variation Across States. Health Aff (Millwood). 2017;36(5):909-17.

17. Chakrabarti S. Usefulness of telepsychiatry: A critical evaluation of videoconferencing-based approaches. World J Psychiatry. 2015;5(3):286-304.

18. Fortney JC, Pyne JM, Mouden SB, Mittal D, Hudson TJ, Schroeder GW, et al. Practice-based versus telemedicine-based collaborative care for depression in rural federally qualified health centers: a pragmatic randomized comparative effectiveness trial. Am J Psychiatry. 2013;170(4):414-25.

19. Eibl JK, Gauthier G, Pellegrini D, Daiter J, Varenbut M, Hogenbirk JC, et al. The effectiveness of telemedicine-delivered opioid agonist therapy in a supervised clinical setting. Drug Alcohol Depend. 2017;176:133-8.

20. Lau Y, Htun TP, Wong SN, Tam WSW, Klainin-Yobas P. TherapistSupported Internet-Based Cognitive Behavior Therapy for Stress, Anxiety, and Depressive Symptoms Among Postpartum Women: A Systematic Review and Meta-Analysis. J Med Internet Res. 2017;19(4):e138.

21. Olthuis JV, Wozney L, Asmundson GJ, Cramm H, Lingley-Pottie P, McGrath PJ. Distance-delivered interventions for PTSD: A systematic review and meta-analysis. J Anxiety Disord. 2016;44:9-26.

22. Simpson SG, Reid CL. Therapeutic alliance in videoconferencing psychotherapy: a review. Aust J Rural Health. 2014;22(6):280-99.

23. Wootton BM. Remote cognitive-behavior therapy for obsessive-compulsive symptoms: A meta-analysis. Clin Psychol Rev. 2016;43:103-13.

24. Busch AB, Sugarman DE, Horvitz LE, Greenfield SF. Telemedicine for treating mental health and substance use disorders: reflections since the pandemic. Neuropsychopharmacology. 2021;46(6):1068-70.

25. Patel SY, Huskamp HA, Busch AB, Mehrotra A. Telemental health and US rural-urban differences in specialty mental health use, 2010-2017. American journal of public health. 2020;110(9):1308-14.

26. Martinez KA, Rood M, Jhangiani N, Kou L, Rose S, Boissy A, et al Patterns of Use and Correlates of Patient Satisfaction with a Large Nationwide Direct to Consumer Telemedicine Service. J Gen Intern Med. 2018;33(10):1768-73.

27. Pai A. UnitedHealthcare now covers Doctor On Demand, American Well video visits too. Mobile Health News. 2015. Available at: https://www. mobihealthnews.com/43052/unitedhealthcare-now-covers-doctor-ondemandamerican-well-video-visits-too. Accessed 4 Sept 2019.

28. Farr C. American Well pulls in $\$ 194$ million to keep up with the skyrocketing demand for telemedicine. CNBC. 2020. Available at: https://www.cnbc.com/2020/05/20/american-well-raises-194-millionas-telemedicine-demandskyrockets.html. Accessed 20 Nov 2020.
29. Ashwood JS, Mehrotra A, Cowling D, Uscher-Pines L. Direct-ToConsumer Telehealth May Increase Access To Care But Does Not Decrease Spending. Health Aff (Millwood). 2017;36(3):485-91.

30. Rastogi R, Martinez KA, Gupta N, Rood M, Rothberg MB. Management of urinary tract infections in direct to consumer telemedicine. Journal of general internal medicine. 2020;35(3):643-8.

31. Martinez KA, Rood M, Jhangiani N, Boissy A, Rothberg MB. Antibiotic Prescribing for Respiratory Tract Infections and Encounter Length: An Observational Study of Telemedicine. Ann Intern Med. 2019;170(4):2757.

32. Martinez KA, Rothberg MB. Antibiotic Prescribing for Respiratory Tract Infections and Encounter Length. Ann Intern Med. 2019;171(2):150.

33. Lingam HA, Caudill RL. Teleprescribing Controlled substances: flowchart analysis of the Ryan Haight Act and state telemedicine laws. Journal of Technology in Behavioral Science. 2019;4(4):346-59.

34. John A, Marchant AL, Fone DL, McGregor JI, Dennis MS, Tan JO, et al. Recent trends in primary-care antidepressant prescribing to children and young people: an e-cohort study. Psychol Med. 2016;46(16):3315-27.

35. Moore M, Yuen HM, Dunn N, Mullee MA, Maskell J, Kendrick T. Explaining the rise in antidepressant prescribing: a descriptive study using the general practice research database. Bmj. 2009;339:b3999.

36. Olfson M, Marcus SC, Pincus HA, Zito JM, Thompson JW, Zarin DA. Antidepressant Prescribing Practices of Outpatient Psychiatrists. JAMA Psychiatry. 1998;55(4):310-6.

37. Clay RA. Mental health apps are gaining traction. Monitor on Psychology. 2021;52(1)

38. Mehrotra A, Jena AB, Busch AB, Souza J, Uscher-Pines L, Landon BE. Utilization of Telemedicine Among Rural Medicare BeneficiariesUtilization of Telemedicine Among Rural Medicare BeneficiariesLetters. JAMA. 2016;315(18):2015-6.

39. Uscher-Pines L, Mehrotra A. Analysis of Teladoc use seems to indicate expanded access to care for patients without prior connection to a provider. Health Affairs. 2014;33(2):258-64

40. Hohman JA, Martinez KA, Anand A, Martyn T, Rood M, Rothberg MB. Use of Direct-to-Consumer Telemedicine for Attention-Deficit Hyperactivity Disorder. Journal of General Internal Medicine. 2020;35:3392-4.

41. Malowney M, Keltz S, Fischer D, Boyd JW. Availability of outpatient care from psychiatrists: a simulated-patient study in three U.S. cities. Psychiatr Serv. 2015;66(1):94-6.

42. Niedzwiecki MJ, Sharma PJ, Kanzaria HK, McConville S, Hsia RY. Factors Associated With Emergency Department Use by Patients With and Without Mental Health Diagnoses. JAMA Netw Open. 2018;1(6):e183528.

43. Kathol RG, Melek S, Sargent G. Mental health and substance use disorder services and professionals as a core part of health in clinically integrated networks. In: Yale KBJ, Konschak C, ed. Clinical Integration: Accountable Care \& Population Health. 3rd ed. Virgina Beach, VA: Convurgent Publishing: 2015.

44. Penchansky R, Thomas JW. The concept of access: definition and relationship to consumer satisfaction. Medical care. 1981:127-40.

45. Martinez KA, Rood M, Jhangiani N, Kou L, Rose S, Boissy A, et al. Patterns of Use and Correlates of Patient Satisfaction with a Large Nationwide Direct to Consumer Telemedicine Service. Journal of General Internal Medicine. 2018;33(10):1768-73.

46. Rohrer JE, Angstman KB, Adamson SC, Bernard ME, Bachman JW, Morgan ME. Impact of online primary care visits on standard costs: a pilot study. Popul Health Manag. 2010;13(2):59-63.

47. Mehrotra A, Uscher-Pines L, Lee MS. The dawn of direct-to-consumer telehealth. Understanding Telehealth. New York: McGraw-Hill Education. 2018:217-23.

48. Olfson M, Marcus SC, Pincus HA, Zito JM, Thompson JW, Zarin DA. Antidepressant prescribing practices of outpatient psychiatrists. Archives of general psychiatry. 1998;55(4):310-6.

49. Sankaranarayanan J, Puumala SE. Antipsychotic use at adult ambulatory care visits by patients with mental health disorders in the United States, 1996-2003: national estimates and associated factors. Clinical therapeutics. 2007;29(4):723-41.

50. Zuvekas SH. Prescription drugs and the changing patterns of treatment for mental disorders, 1996-2001. Health affairs. 2005;24(1):195-205.

51. Olfson M, Marcus SC, Druss B, Elinson L, Tanielian T, Pincus HA. National trends in the outpatient treatment of depression. Jama. 2002;287(2):203-9.

52. Perelman School of Medicine, University of Pennsylvania. Center for Cognitive Therapy - Frequently Asked Questions. Department of Psychiatry. 2019. Available at: https://www.med.upenn.edu/cct/faq.html. Accessed 24 Aug 2019. 
53. The Counseling Hub. How long does each counseling session last? Available at: https://thecounselinghub.com/how-long-does-a-sessionlast. Accessed: 24 Aug 2019.

54. Olfson M, Cherry DK, Lewis-Fernández R. Racial Differences in Visit Duration of Outpatient Psychiatric Visits. JAMA Psychiatry. 2009;66(2):214-21.

55. Shaw MK, Davis SA, Fleischer AB, Feldman SR. The duration of office visits in the United States, 1993 to 2010. Am J Manag Care. 2014;20(10):820-6.

56. Barnett ML, Ray KN, Souza J, Mehrotra A. Trends in Telemedicine Use in a Large Commercially Insured Population, 2005-2017. Jama. 2018;320(20):2147-9.

57. Services CfMaM. Contract Year 2020 Medicare Advantage and Part D Flexibility Final Rule (CMS-4185-F). 2019

58. Eylem O, De Wit L, Van Straten A, Steubl L, Melissourgaki Z, Danışman GT, et al. Stigma for common mental disorders in racial minorities and majorities a systematic review and meta-analysis. BMC Public Health. 2020;20:1-20.

59. Lam K, Lu AD, Shi Y, Covinsky KE. Assessing telemedicine unreadiness among older adults in the United States during the COVID-19 pandemic. JAMA internal medicine. 2020;180(10):1389-91.

60. Bauer MS, Krawczyk L, Tuozzo K, Frigand C, Holmes S, Miller CJ, et al. Implementing and Sustaining Team-Based Telecare for Bipolar Disorder: Lessons Learned from a Model-Guided, Mixed Methods Analysis. Telemed J E Health. 2018;24(1):45-53.

61. Godleski L, Nieves JE, Darkins A, Lehmann L. VA telemental health suicide assessment. Behav Sci Law. 2008;26(3):271-86.
62. Norman S. The use of telemedicine in psychiatry. Journal of psychiatric and mental health nursing. 2006;13(6):771-7.

63. Darkins A. The growth of telehealth services in the Veterans Health Administration between 1994 and 2014: a study in the diffusion of innovation. Telemedicine and e-Health. 2014;20(9):761-8.

64. Petersen H. Connecting veterans with telehealth. US Department of Veterans Affairs. 2018

65. Drago A, Winding TN, Antypa N. Videoconferencing in psychiatry, a metaanalysis of assessment and treatment. Eur Psychiatry. 2016;36:29-37.

66. Ruskin PE, Silver-Aylaian M, Kling MA, Reed SA, Bradham DD, Hebel JR et al. Treatment outcomes in depression: comparison of remote treatment through telepsychiatry to in-person treatment. American Journal of Psychiatry. 2004;161(8):1471-6.

67. Zarate Jr CA, Weinstock L, Cukor P, Morabito C, Leahy L, Burns C, et al. Applicability of telemedicine for assessing patients with schizophrenia: Acceptance and reliability. The Journal of clinical psychiatry. 1997.

68. Kasckow J, Felmet K, Appelt C, Thompson R, Rotondi A, Haas G. Telepsychiatry in the assessment and treatment of schizophrenia. Clinical schizophrenia \& related psychoses. 2013;8(1):21-7A.

69. McGuire TG, Miranda J. New evidence regarding racial and ethnic disparities in mental health: Policy implications. Health Affairs. 2008;27(2):393-403.

70. Konrad TR, Ellis AR, Thomas KC, Holzer CE, Morrissey JP. County-level estimates of need for mental health professionals in the United States. Psychiatric Services. 2009;60(10):1307-14

Publisher's Note: Springer Nature remains neutral with regard to jurisdictional claims in published maps and institutional affiliations. 